\title{
CAUSES AND PROPOSED RESOLUTIONS OF HIGH VIBRATION IN NWTF TRANSFER PUMPS (U)
}

by

B. J. Trawinski

Westinghouse Savannah River Company

Savannah River Site

Aiken, South Carolina 29808

DOE Contract No. DE-AC09-89SR 18035

This paper was prepared in connection with work done under the above contract number with the U.S.

Department of Energy. By acceptance of this paper, the publisher and/or recipient acknowledges the U. S. Government's right to retain a nonexclusive, royalty-free license in and to any copyright covering this paper, along with the right to reproduce and to authorize others to reproduce all or part of the copyrighted paper. 


\section{DISCLAIMER}

This report was prepared as an account of work sponsored by an agency of the United States Government. Neither the United States Government nor any agency thereof, nor any of their employees, makes any warranty, express or implied, or assumes any legal liability or responsibility for the accuracy, completeness, or usefulness of any information, apparatus, product, or process disclosed, or represents that its use would not infringe privately owned rights. Reference herein to any specific commercial product, process, or service by trade name, trademark, manufacturer, or otherwise does not necessarily constitute or imply its endorsement, recommendation, or favoring by the United States Government or any agency thereof. The views and opinions of authors expressed herein do not necessarily state or reflect those of the United States Government or any agency thereof.

This report has been reproduced directly from the best available copy.

Available to DOE and DOE contractors from the Office of Scientific and Technical Information, P. O. Box 62, Oak Ridge. TN 37831; prices available from (615) $576-8401$.

Available to the public from the National Technical Information Service, U. S. Deparment of Commerce, 5285 Port Royal Rd., Springfield, VA 22161 
WSRC-TR-93-452, Rev. 0, B.J. Trawinski to Distribution, "Causes and Proposed Resolutions of High Vibration in NWTF Transfer Pumps (U)", October 22, 1993.

\section{DISTRIBUTION:}

T.M. Monahon, 703-H

C.L. Sharpe, 703-H

V.G. Dickert, 703-H

G.O. Percival, 704-56H

H.M. Handfinger, 704-56H

G.R. Huff, 704-56H

R.L. Salizzoni, 707-H

R.W. Smith, BTC B20-006

S.A. Saunders, 241-102H

G.E. Abell, 988-W

A.S. Greer, 241-102H

W.E. Perry, 988-W

E.L. Yoder, 241-102H

NWTF File 1100.8, 241-102H

J.B. Crosby, 241-102H

HLWE Fileroom, File 166.6, 703-H

B.J. Amold, 241-102H 
HIGH LEVEL WASTE ENGINEERING SECTION

HLW H-AREA COGNIZANT ENGINEERING GROUP
WSRC-TR-93-452

REVISION: 0

KEYWORDS:

High Level Waste Engineering

New Waste Transfer Facility

Transfer Pumps

Vibration

\section{RETENTION:}

Permanent

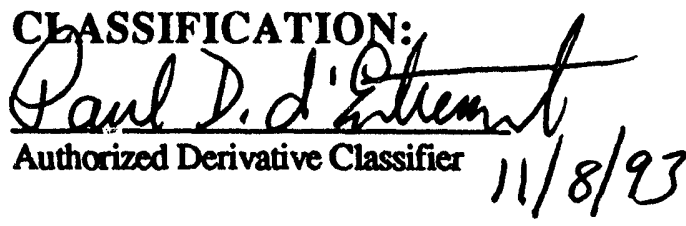

\section{CAUSES AND PROPOSED RESOLUTIONS OF HIGH VIBRATION IN NWTF TRANSFER PUMPS (U) \\ BY}

\section{B. J. TRAWINSKI}

ISSUED: OCTOBER 22, 1993



Technical Reviewer

Date: $10 / 22 / 93$

Manager, NWTF Cognizant Engineering Group

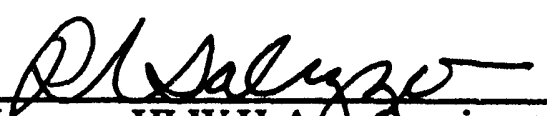

Manager, HLW H-Afed ${ }^{\circ}$ ognizant Engineering Section

\section{E. Leow Yoder}

Manager, NW F Startup Group

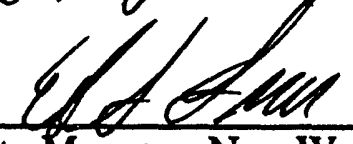

Facility Manager, New Waste Transfer Facility

Date: $11 / 5 / 93$

Date: $11 / 8 / 93$

Date: $11 / 08 / 93$ 
WSRC-TR-93-452

Revision 0

Page 2

\section{INTRODUCTION}

This Technical Report is intended to communicate the findings from the latest phase of New Waste Transfer Facility (NWTF) transfer pump testing. These tests have identified causes for the high pump vibrations that have been observed during previous phases of transfer pump startup testing, and have led to recommendations for resolving the vibration problem.

\section{SUMMARY}

A series of diagnostic tests was conducted from July 30 to August 4 under procedure NWTF-CR436. The purpose of these tests was to conclusively identify causes of high vibration which had been recorded during previous startup testing of the NWTF Transfer Pumps.

System resonance was suspected from the previous tests, and these tests confirmed this theory. A strong relationship is established between tank-top loading and vibration levels -- the added weight of a second pump installed on the tank results in a $70 \%$ reduction in peak vibration levels. Tank liquid level has an insignificant effect on vibration.

The evidence also indicates that certain pumps are more prone to vibration than others when the two are installed in various system configurations. For the two pumps studied, one exhibited $67 \%$ lower vibration levels than the other.

The preferred solution to the pump vibration problems is to rework the system design or the pump design as necessary to eliminate the excessive vibration over the full range of running speeds. If modification or rework are not possible or cannot be justified, then the alternate recommendations made at the end of this report may be considered.

These alternate recommendations focus on establishing maximum speed requirements for each pump location and determining whether certain pumps should be moved from their present location to locations where speed requirements are lower or the system provides more damping.

Recommendations are also made to establish an optimal tank-top load and to pursue correction of vibration-prone pumps if relocation of pumps does not solve all vibration problems.

\section{DISCUSSION}

\section{Background}

Previous operational testing [Reference 6] of the NWTF Transfer Pumps had shown that two pumps had acceptable vibration, one pump had marginally unacceptable vibration, and two pumps had severe vibration. One pump has not been tested due to shaft alignment problems. Vibration levels in all operated pumps showed a sharp increase as pump speed neared the $3000 \mathrm{rpm}$ maximum.

Vibration in NWTF Transfer Pumps presents a major problem, as it can shorten pump life, reduce pump performance, and lead to premature failure of other in-cell components (for example, waste jumpers) due to cyclic loading. It is important to address this problem now, before hot start-up of NWTF, so that a satisfactory solution can be obtained.

A major limitation of the previous tests was that the pump was run only at certain speeds rather than over a continuous range. Therefore, the possibility existed that high vibrations were missed on the two pumps which were thought to have acceptable vibration. Initial impact and coastdown tests performed during this phase indicated that vibration could peak at lower than top speeds, and that vibration might be caused by a resonance. It was unclear whether the resonance resided in the pump itself, or in a system of which the pump is a component. 
WSRC-TR-93-452

Revision 0

Page 3

\section{DISCUSSION (Cont'd)}

\section{Background (Cont'd)}

A second limitation of the previous tests was that configuration was not controlled -- i.e., the number of pumps installed on tanks was not known, tank liquid level was not always recorded, and all process/electrical jumpers were not installed. Thus the system was not well defined, and was not always consistent from test to test.

Action Plan WER-HLE-930885 [8] was developed to define the test program to determine the source if the vibration and to correct the vibration. Procedure NWTF-CR-436 [7] was the first phase of this test program.

\section{Basic Questions}

The basic questions that procedure NWTF-CR-436 sought to answer were as follows:

- What is the cause of the excessive pump vibration? Is it the pump itself, or is it a property of the system in which the pump is installed?

- If the cause of the excessive vibration is determined to be system-related, what potential system parameters affect the vibration? Does the installation of a second pump onto the tank top affect the vibration of the operating pump? Does the liquid level in the tank affect the vibration of the operating pump?

\section{Test Methodology}

Procedure NWTF-CR-436 provided direction for ten sets of tests to be performed. Each set of tests consisted of an impact test on each of two pumps, a measurement of vibration at top running speed on the operating pump, and a coastdown test on the operating pump. An accelerometer was magnetically mounted on point UY (defined in procedure NWTF-CR-436) for all tests. Point UY is in the plane of the upper pump bearing.

Testing was done in H-Pump Tank 10 (HPT10), using two pumps: serial numbers $\mathrm{N}-20320$ (intended location - HPT9) and N-20321 (intended location - HPT10). These two pumps were chosen on the basis of their vibration histories, so that one pump with a history of acceptable vibration (N-20321) and one pump with a history of excessive vibration ( $\mathrm{N}-20320)$ would be used.

HPT10 in normal operation will have a pump installed only in the west pump port. The east pump port will have a stainless steel cover. However, for procedure NWTF-CR-436, certain tests required a second pump to be installed in the east port. For the remaining tests, the east port was open, with no pump or cover plate installed. Only the pump. installed in the west port can be operated.

The intent of the procedure was to study the effects of changes to three variables:

- Operable Pump: Defined as the pump installed in the west port of HPT10 at any given time. This variable can have the values $\mathrm{N}-20320$ or $\mathrm{N}-20321$ (serial numbers of pumps used in these tests).

- Tank-Top Loading: Defined as the added load produced by the installation of a second pump into the east port of HPT10. Data can be taken with a second pump installed or removed. 
WSRC-TR-93-452

Revision 0

Page 4

\section{DISCUSSION (Cont'd)}

\section{Test Methodology (Cont'd)}

- Tank Liquid Level: Defined as the liquid level in HPT10 as read from the DCS level indicators. Can have values of 65 or 85 inches.

Between each of the ten sets of tests, one of these three variables were changed. The resulting data from these tests could be grouped in various ways to show the effects of changes to any one of the three variables, when the other two variables are held constant.

The equipment used to obtain data for these tests included:

- $\quad$ Category 1 M\&TE Vibration Analyzer (CSI Model 2115)

- $\quad$ Category 1 M\&TE Vibration Probe with magnetic mount

- $\quad$ Category 1 M\&TE Optic:! Tachometer

\section{Observations}

\section{Operable Pump Varied (Tank-Top Loadine and Tank Liquid Level Constant)}

Peak vibration levels for N-20321 pump were lower compared to N-20320 levels in all four cases examined. N-20321 levels were on average 67\% lower than N-20320 levels, with a standard deviation of 4\%. See Attachment 2 for plots, and Attachment 6 for calculations.

\section{Tank-Top Loading Varied (Operable Pump and Tank Liquid Level Constant)}

Installation of a pump in the east port of HPT10 lowers the frequency of peak vibration and the first impact frequency by approximately $2 \mathrm{~Hz}$. The added mass therefore lowers the system natural frequency further into the operating range (maximum of operating range is $3000 \mathrm{rpm}$, or $50 \mathrm{~Hz}$ ).

However, the installation of the second pump also provides significant damping, such that the peak vibration is reduced in all four cases examined. The mean reduction was $70 \%$, with a standard deviation of $3 \%$.

Refer to Attachments 1 and 3 for plots, and Attachment 6 for calculations.

\section{Tank Liquid Level Varied (Operable Pump and Tank-Top Loadine Constant)}

While variations in liquid level appear to affect the frequencies of vibrations, there is no significant effect on the amplitude of peak vibration. See Attachment 4 for plots, and Attachment 6 for calculations.

\section{Conclusions}

\section{Pump Can Be Source of Some Vibrations}

The data demonstrated that for a given system configuration and tank level, N-20321 pump vibration levels were $67 \%$ lower than N-20320 levels. The conclusion is that the N-20320 pump is more prone to vibration. Stated another way, the N-20321 pump is "better" at higher speeds than the N-20320 pump. This finding may affect the placement of the NWTF Transfer Pumps: i.e., the $\mathrm{N}-20321$ pump is better suited for applications requiring near-maximum operating speeds. 
WSRC-TR-93-452

Revision 0

Page 5

\section{DISCUSSION (Cont'd)}

\section{Conclusions (Cont'd)}

\section{Installation of a Second Pump in the East Port of HPTlO Reduces Vibration}

Even though the added mass on the tank top reduces natural frequencies further down into the operating range of the pumps (as expected), it also provides damping that results in a 70\% reduction in vibration levels. Therefore, in tanks with only one pump installed, adding mass to the east port (spare) should result in reduced vibration levels, if it is necessary to operate the pumps in these tanks at high rpm.

It should be noted that HPT7 is designed with two installed pumps. Testing must be done to verify that additional mass is not needed.

\section{Changing Tank Water Level Does Not Significantly Affect Vibration Levels}

The data showed no significant effects of changing tank water level on peak vibration levels.

\section{PRIMARY RECOMMENDATIONS}

\section{Modify System and/or Rework Pumps to Meet Project Performance Requirements}

The preferred solution to the pump vibration problems is to rework the system design or the pump design as necessary to eliminate the excessive vibration over the full range of running speeds. The vibration acceptance criteria must be reviewed and reconsidered as recommended below. If modification or rework are not possible or cannot be justified, then the recommendations listed on the following pages may be considered.

\section{Establish Acceptance Criteria for Transfer Pump Vibration Levels}

Previous testing had used an acceptance criteria of 0.2 inches/second peak velocity, based on SRS guidelines [5]. However, the specification under which the pumps were purchased [3], lists an acceptance criteria of 0.003 inches peak-to-peak displacement. This displacement converts to a velocity of 0.471 inches/second at $3000 \mathrm{rpm}$, and decreases linearly with pump speed to 0 inches/second at $0 \mathrm{rpm}$. It equals 0.2 inches/second at a pump speed of $1273 \mathrm{rpm}$.

It is impractical to demand that the pumps vibrate at lower levels than the original specification permitted. Therefore, it is recommended that the acceptance criteria for all NWTF Transfer Pumps be established at:

- $\quad 0.2$ inches/second for pump speeds $\leq 1273 \mathrm{rpm}$; and

- $(0.000157 \times \mathrm{rpm})$ inches/second for pump speeds $>1273 \mathrm{rpm}$

See Attachment 7 for plot.

A maximum vibration of 0.2 inches/second for pump speeds up to $1273 \mathrm{rpm}$ will allow the pumps to startup with minimum vibration without interlocking at low speeds.

If this recommendation is accepted, Design Engineering must validate this new acceptance criteria.

Additionally, an analysis is required to establish the acceptance criteria for pump-induced pipe vibration. Effects on wall nozzles, wall penetrations, and equipment attached to the tank must be considered. 
WSRC-TR-93-452

Revision 0

Page 6

\section{ALTERNATE RECOMMENDATIONS}

\section{Locate Pumps Based on Past Vibration History and Projected Use (If Necessary)}

Total head requirements have been projected for each pump location, based on expected fluids and expected destinations [1,2]. Except for the H-to-F interarea transfer pump (located in the east port of HPT7), the maximum head requirement necessary to produce a $100 \mathrm{gpm}$ flow is $166 \mathrm{feet}$. For the H-to-F pump, the required head is 460 feet.

Pump performance data supplied by the manufacturer [4] shows that the NWTF Transfer Pumps pump $100 \mathrm{gpm}$ at a pressure of between 183 and 191 feet when operating at $2000 \mathrm{rpm}$. Therefore, for all applications but the H-to-F pump, the data indicates that the pumps will have to operate at no more than $2000 \mathrm{rpm}$ to provide the required flow. The H-to-F pump can be expected to require operating speeds close to $3000 \mathrm{rpm}$.

Testing to date has shown no vibration problems at pump speeds up to $2000 \mathrm{rpm}$. Two of the five tested pumps (serial numbers $\mathrm{N}-20318$ and $\mathrm{N}-20320$ ) will vibrate severely as speeds approach $3000 \mathrm{rpm}[6]$. Pump N-20318 is currently designated as the H-to-F pump.

It is recommended that the pumps known to have low vibration be used in applications requiring high speeds (H-to-F pump) or high reliability (DWPF recycle waste - HPT10, and spare pump). Ranking these three applications in order of importance (arbitrary), and assigning a pump to each application, yields:

1. H-to-F transfers (N-20321)

2. Spare (N-20322)

3. DWPF recycle (N-20319)

It is expected that Operations will establish the actual order of importance.

It is recommended that the remaining pumps be used in the remaining applications, which are characterized by lower required speeds, lower frequency of use, and lower importance.

If implemented, these recommendations would require significant controls to ensure that the pumps and their locations are configuration-controlled accordingly.

An additional recommendation is to program the Variable Frequency Drives for HPT8, HPT9, and HPT10 so that operating speed is limited to the anticipated maximum required, plus a reasonable cushion.

\section{Confirm Original Design Calculations}

It is recommended that the original calculations for total pump head requirements be checked against the present design, in order to ensure that requirements have not changed and to verify required pump speeds for each application prior to testing.

Test Pumps in New Locations to Ensure Acceptable Vibration at Required Speeds (If Necessary)

Once the final location of each pump is established, the pump should be operated, and should exhibit acceptable vibration at all speeds up to the maximum speed for that application. For speeds above the maximum for the application, vibrations in excess of the acceptance criteria may be 
WSRC-TR-93-452

Revision 0

Page 7

\section{ALTERNATE RECOMMENDATIONS (Cont'd)}

\section{Test Pumps in New Locations to Ensure Acceptable Vibration at Required Speeds (If Necessary) (Cont'd)}

dispositioned "Use As-Is." It is imperative that all equipment and jumpers be installed on the tank in question, so that normal operating conditions are simulated.

It is also suggested that rundown tests, in which the pump speed is slowly lowered, be used in place of coastdown tests, where the pump is shut off. In coastdown, deceleration from top speed is too fast for the vibration analyzer, resulting in poor resolution. The correct peak vibration level will probably be recorded, but it will be displayed at a lower than actual frequency due to delays in the analyzer synchronizing circuitry. Rundown tests also match actual operating conditions. See Attachment 5 for a comparison of coastdown and rundown tests.

\section{Load Tank Top to Reduce Vibration (If Necessary)}

If unacceptable vibrations occur in the relocated pumps in HPT8, HPT9, and HPT10, it is recommended that tank-top loading be attempted. The tests discussed in this report have shown that a significant damping effect is produced by adding mass to the east port of HPT10; it is expected that this also holds true for HPT8 and HPT9. HPT7 already has two pumps installed, and thus additional damping should not be required.

\section{Return Pumps to Vender for Correction of Pump Vibration (If Necessary)}

The tests discussed in this report showed that the $\mathrm{N}-20320$ pump has a vibration problem that is not caused by the system resonance. The $\mathrm{N}-20318$ pump has experienced similar vibration levels [6], and is expected to also have a pump-induced vibration. If implementation of the recommendations listed above does not reduce vibration in these pumps to acceptable levels, then these pumps should be returned to the vendor for testing and repairs.

\section{Recommendations for Euture Pump Procurement (Long-Term)}

Pumps procured in the future as NWTF spares/replacements should be tested in a system similar to the one in which they are expected to operate. Additionally, a vibration acceptance criteria of 0.2 in/sec at all speeds should be specified, in order to ensure compliance of the replacement pumps with current guidelines. These stringent standards are necessary because after NWTF start-up, there will be no opportunity to test these pumps in-place. 
WSRC-TR-93-452

Revision 0

Page 8

\section{REFERENCES}

1. Nujent, A. J., "Committed Calculation: Total Differential Head Requirements, Available NPSH, and Brake Horsepower for the NWTF Transfer Pumps," Job No. 13239, Calculation No. 518M500, October 17, 1986.

2. System Head Curves for NWTF Transfer Pumps, Job No. 13239, Data Sheets DS-M11914.1, DS-M119-15.1, DS-M119-16.1, DS-M119-17.1, and DS-M119-18.1, Revision 0 (all), January 5, 1987.

3. Technical Specification for Interarea Transfer Pumps and New Waste Transfer Facility Transfer Pumps for the Defense Waste Processing Facility. DA S-511 and Y-518, Job No. 13239, Specification No. M-119, Revision 4, Bechtel National Inc. Advanced Technology, May 24, 1989.

4. Eargle, J. C. to G. H. Street, "Interarea Transfer Pump Performance Data (U)," DP-89-0058, August 11, 1989.

5. "Equipment Vibration," SRS Engineering Guide 15242-01-G, Revision 0, September 30, 1992, in SRS Engineering Standards Manual (U): Mechanical - Other, WSRC-TM-92-10-7BK-3.

6. Trawinski, B. J. to Distribution, "NWTF Transfer Pump Test Results for the Period 2/22/93 to 6/11/93 (U)," WER-HLE-930881, Revision 0, June 24, 1993.

7. "General Pump Vibration Diagnostic Tests in HPT10 (U)," Special Procedure NWTF-CR436, July 21, 1993.

8. Trawinski, B. J. to Distribution, "NWTF Transfer Pump Problem Resolution Action Plan (U)," WER-HLE-930885, Revision 0, July 26, 1993. 
WSRC-TR-93-452

Revision 0

Page 9

\section{ATTACHMENTS}

- Attachment 1

- Attachment 2

- Attachment 3

- $\quad$ Attachment 4

- Attachment 5

- Attachment 6

- $\quad$ Attachment 7

All attachments are two pages in length. 


\section{Attachment 1, page 1 of 2}

\section{Summary}

Natural frequency data from four impact tests are shown on page 2 of this attachment. These data demonstrate a correlation between tank top loading and measured natural frequencies.

\section{Parameters}

The status of the experiment parameters was as follows:
Tank-top loading
VARIED
Operable pump
CONSTANT
Tank water level
CONSTANT

\section{Discussion}

The two plots on the left represent data obtained at different times on the N-20321 pump. For both plots, the N-20321 pump was bolted down in the west port of HPT10.

The two plots on the right represent data obtained at different times on the N-20320 pump. The N20320 pump was installed in the east port of HPT10 for the lower ("reference") plot, and was suspended from the bridge crane in the upper ("comparison") plot.

The methodology was as follows: (1) the "reference" impact test spectra were obtained; (2) the N20320 pump was raised out of the east port of HPT10; and (3) the "comparison" impact test spectra were obtained.

Therefore, the N-20321 reference spectrum (lower left plot) represents the case where the HPT10 tank top supports an additional load. In the $\mathrm{N}-20321$ comparison spectrum (upper left plot), this load has been removed.

\section{Results}

Removing the N-20320 pump from the east port of HPT10 causes significant changes in the natural frequencies observed on the N-20321 pump -- natural frequency peaks of 48.4 and 60.6 $\mathrm{Hz}$ with the additional tank top loading changed to a single natural frequency peak of $50.5 \mathrm{~Hz}$ after the additional load was removed.

\section{Conclusions}

If the natural frequencies observed on the pumps were related to the pump alone, no change in the natural frequency should have resulted from changing the tank-top loading. However, the results indicate that a change does occur, and therefore, the measured natural frequencies are that of a system composed of the pump, tank top (or entire tank), and other tank-top loads (i.e., another pump installed). 
Attachment 1, page 2 of 2
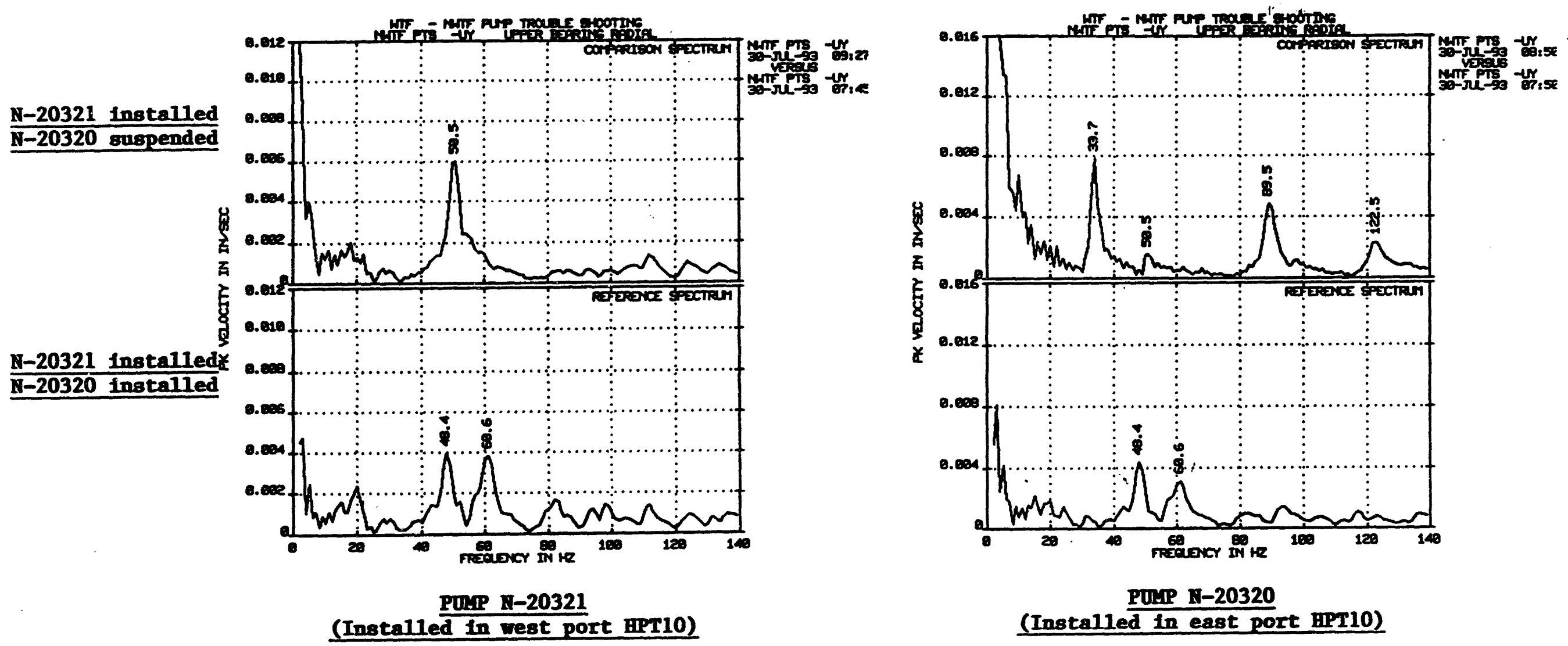


\section{Attachment 2, page 1 of 2}

\section{Summary}

Peak vibration data from four sets of coastdown tests are shown on page 2 of this attachment. These data demonstrate a correlation between tank-top loading and peak vibration amplitudes at high (2500-3000 rpm) operating speeds.

\section{Parameters}

Within each of the four plots shown, the status of the experiment parameters was as follows:

Tank-top loading VARIED

Operable pump CONSTANT

Tank water level CONSTANT

Between the four plots, the operable pump and/or the tank water level are varied.

\section{Discussion}

Coastdown data is always taken on the operable pump. Each plot compares the coastdown test where additional tank-top loading is present (i.e., an additional pump installed in the east port of HPT10) with the coastdown test where the additional load has been removed. Each plot thus studies the effect produced only by changes in tank-top loading.

\section{Results}

In all four cases, removing the additional tank-top load resulted in a significant increase in vibration levels on the operable pump. This occurred at operating speeds approaching $3000 \mathrm{rpm}$.

Also, the frequency at which maximum vibration (a natural frequency) occurred appears to increase as tank-top loading is reduced. This is consistent with the expectation that reduced system mass should result in an increased system natural frequency.

\section{Conclusions}

The results indicate that reducing tank-top loading by removing the second pump increases both natural frequency and amplitude.

While the change in natural frequency is expected (dependent on the square root of mass ${ }^{-1}$ ), the amplitude was expected to remain constant, since it is not dependent in any way on system mass in the simplest, first-order, case. Amplitude can only increase if damping is reduced. Therefore, there is somehow a reduction in system damping that occurs simultaneously with the reduction in system mass. 
Attachment 2, page 2 of 2

\section{CASB 1:}

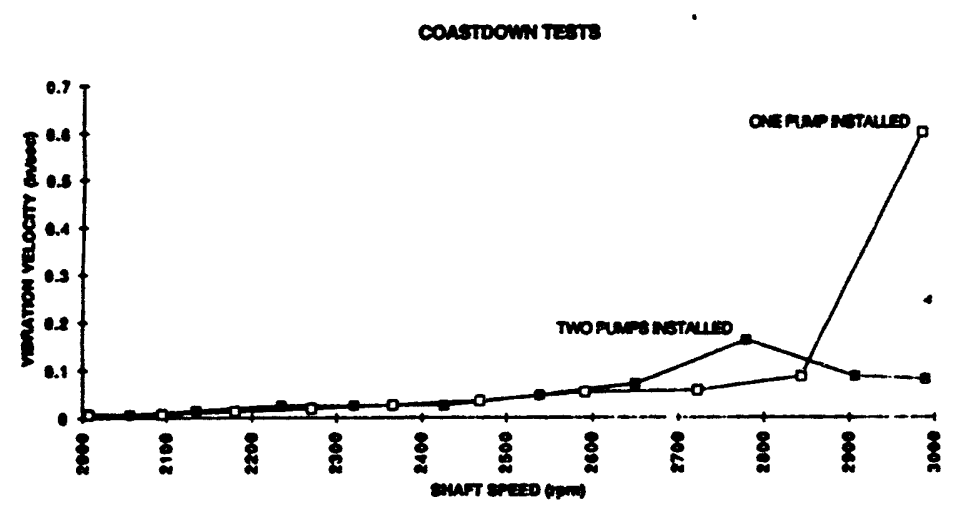

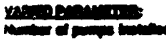

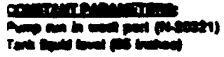

morrenos outa ome

\section{CASE 2:}

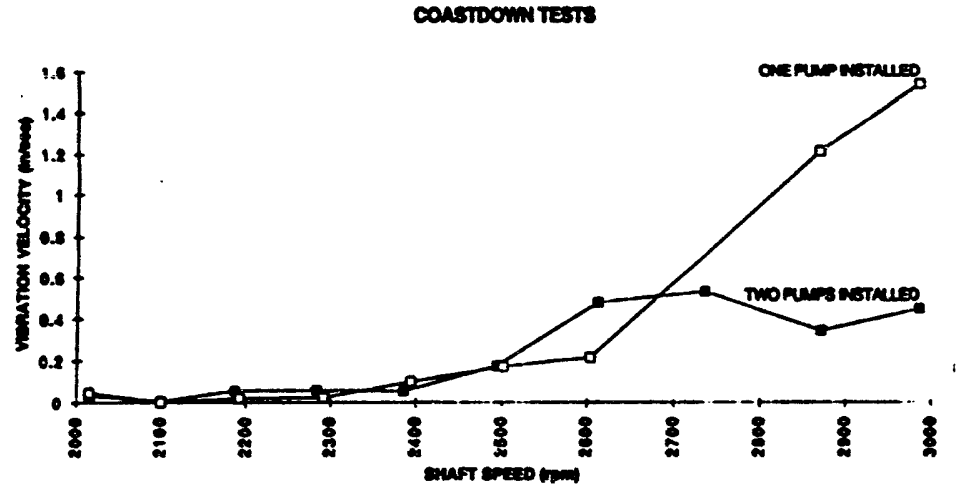

\section{CASE 3:}
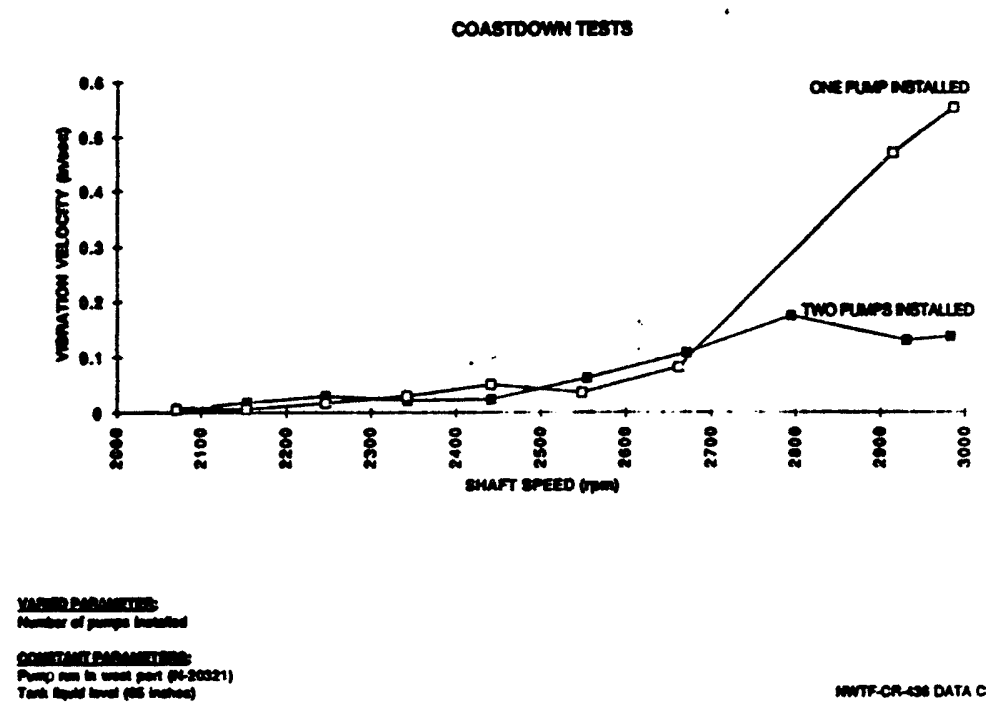

murecros dats crens

\section{CASE 4:}

COASTDOWN TESTS



س.m.






\section{Attachment 3, page 1 of 2}

\section{Summary}

Peak vibration data from four sets of coastdown tests are shown on page 2 of this attachment. These data demonstrate a correlation between the operable pump and peak vibration amplitudes at high (2500-3000 rpm) operating speeds.

\section{Parameters}

Within each of the four plots shown, the status of the experiment parameters was as follows:

Tank-top loading CONSTANT

Operable pump VARIED

Tank water level CONSTANT

Between the four plots, the tank-top loading and/or the tank water level are varied.

\section{Discussion}

Coastdown data is always taken on the operable pump. Each plot compares the coastdown test where $\mathrm{N}-20320$ is the operable pump with the coastdown test where $\mathrm{N}-20321$ is the operable pump. Each plot thus studies the effect produced only by changes in the operable pump.

\section{Results}

In all four cases, the $\mathrm{N}-20320$ pump exhibited significantly higher vibration levels than the $\mathrm{N}$ 20321 pump when installed in an identically-configured system.

\section{Conclusions}

The results indicate that the $\mathrm{N}-20320$ pump exhibits a higher vibration than $\mathrm{N}-20321$ independent of the system. This demonstrates that $\mathrm{N}-20320$ has some type of mechanical problem. Shaft/impeller imbalance is a possibility, and should be investigated if $\mathrm{N}-20320$ is to be operated at speeds over $2000 \mathrm{rpm}$. 
Attachment 3, page 2 of 2

\section{CASE 1:}

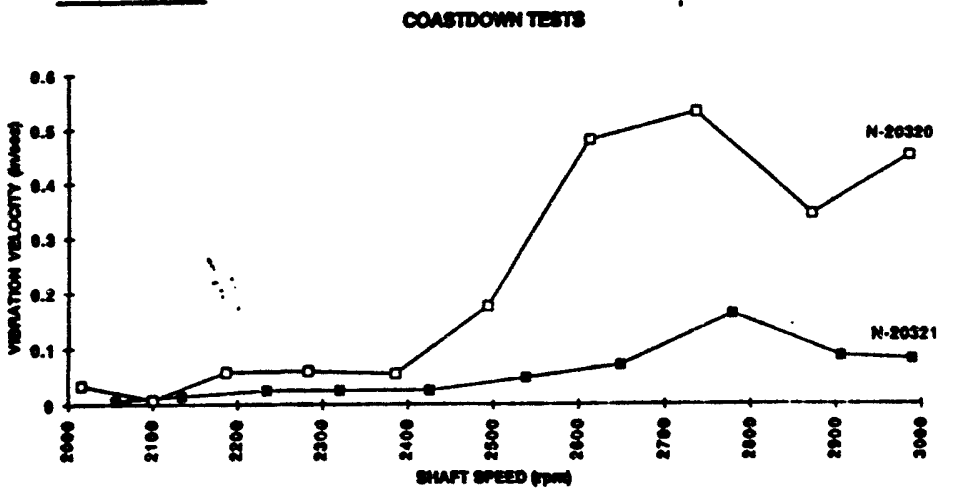

\section{mintm}

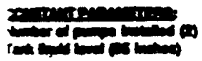



\section{CASE 2:}

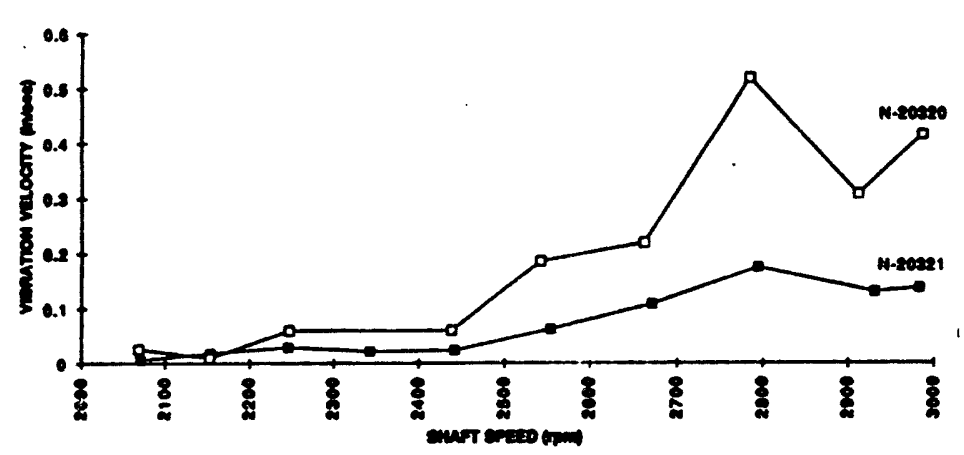

$-m$

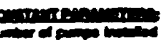

\section{CASE 3:}



\section{ximis}

$=$

mirecenesouta orm 12

\section{CASE 4:}

CONSTOOWN TESTS

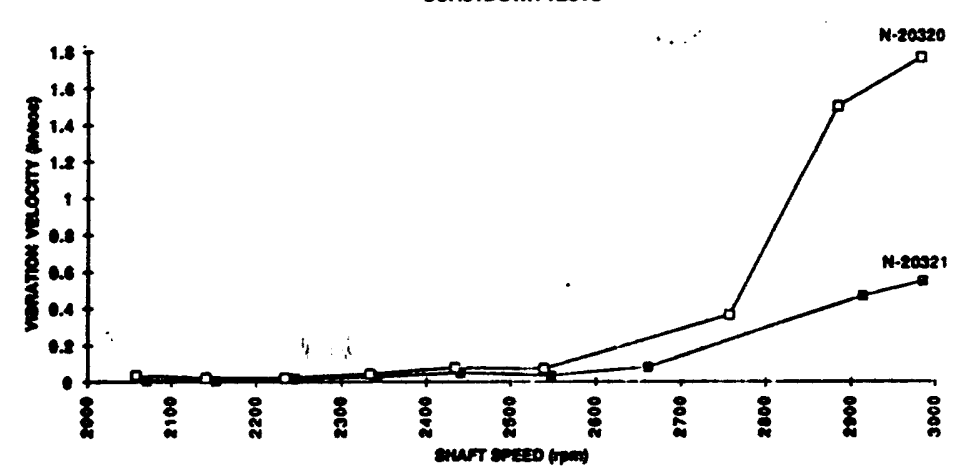

minge

$x=$ 


\section{Attachment 4, page 1 of 2}

\section{Summary}

Peak vibration data from four sets of coastdown tests are shown on page 2 of this attachment. These data show no clear correlation between the tank water level and peak vibration amplitudes.

\section{Parameters}

Within each of the four plots shown, the status of the experiment parameters was as follows:

Tank-top loading $\quad$ CONSTANT

Operable pump CONSTANT

Tank water level VARIED

Between the four plots, the tank-top loading and/or the operable pump are varied.

\section{Discussion}

Coastdown data is always taken on the operable pump. Each plot compares the coastdown test where the tank water level is $\mathbf{8 5}$ inches with the coastdown test where the tank water level has been reduced to 65 inches. Each plot thus studies the effect produced only by changes in the tank water level.

\section{Results}

In all four cases, the changes in tank water level had no appreciable effect on peak vibration amplitudes, although it may affect the natural frequency (data is inconclusive).

\section{Conclusions}

Vibration levels do not appear to depend strongly on tank water level. 


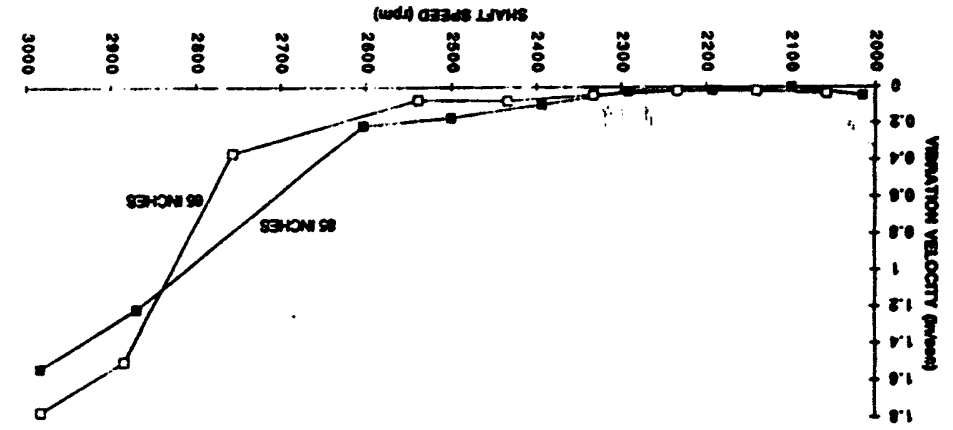

sisal mmocervos

\section{$\overline{: 7 \text { aSv }}$}

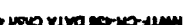

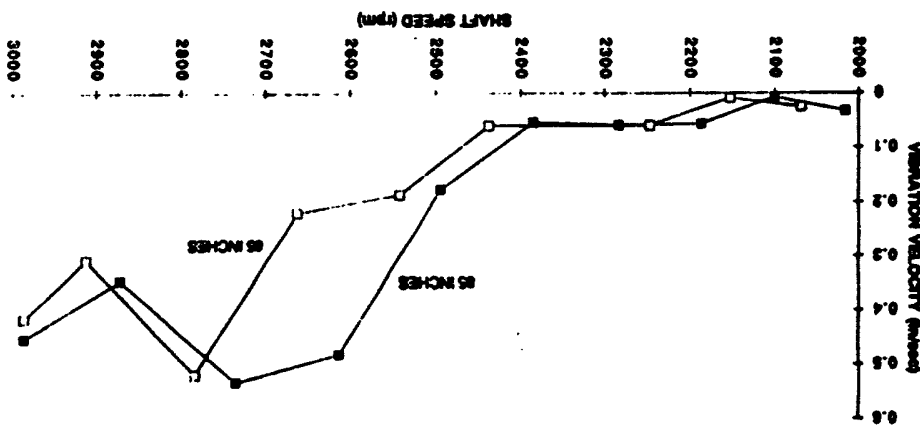

sicen nunourvos



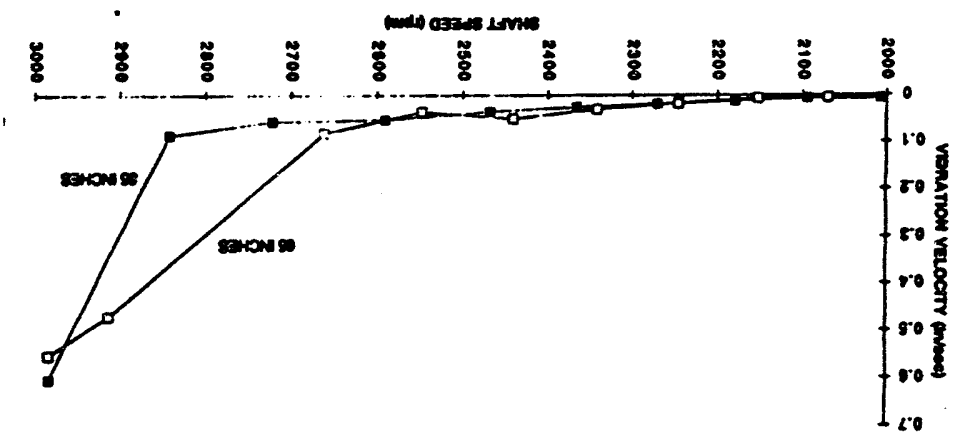

s.sal monousvos

$\overline{: E \text { ISFD }}$

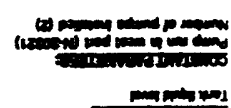

animing

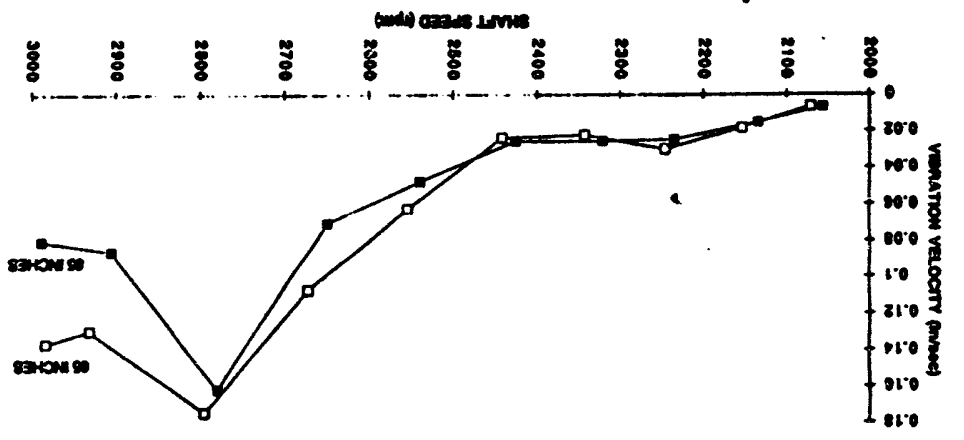

resimaniswos

$\overline{: I \text { aSF }}$

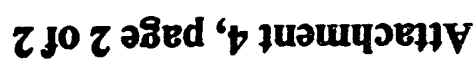




\section{Attachment 5, page 1 of 2}

\section{Summary}

Coastdown and rundown test data obtained in succession on one pump are plotted on page 2 of this attactiment. The coastdown test is shown to yield a peak vibration that is nearly identical in magnitude to the peak produced by the rundown test, but the coastdown test places this peak at a much lower running speed than does the rundown test.

\section{Discussion}

The methodology was as follows: (1) the vibration probe was mounted to the pump motor, and the optical tachometer was aimed at the shaft -- both the probe and the tachometer are connected to a vibration analyzer, which is set up to obtain peak vibration velocity vs. shaft speed data; (2) the pump was brought to full speed; (3) the pump was shut down, and coastdown test data were recorded; (4) the pump was restarted and returned to full speed; (5) the speed of the pump.was gradually reduced, and rundown test data were taken.

In coastdown mode, shaft speed dropped from 3000 to $2500 \mathrm{rpm}$ in approximately one second, whereas in rundown mode, the same drop from 3000 to $2500 \mathrm{rpm}$ was accomplished in approximately 90 seconds. Since the sampling rate of the analyzer does not change, a slower reduction in shaft speed allows more samples to be taken, resulting in a more well-defined peak vibration velocity vs. shaft speed curve. Note that, since the analyzer is configured to capture the peak vibration associated with each sample, the number of samples obtained will not affect the maximum peak vibration obtained over a large range.

\section{Results}

Peak vibration velocities of approximately $0.29 \mathrm{in} / \mathrm{sec}$ were recorded in both the coastdown and rundown tests.

The running speed associated with the peak vibration in the coastdown test was approximately 100 rpm less than that given by the rundown test. The rundown test also showed more peaks than did the coastdown test.

\section{Conclusions}

For obtaining peak vibration data over a large range of running speeds, the coastdown test yields accurate results in a short time period. However, the coastdown test does not accurately depict the shaft speed at which the peak vibration occurs, nor does it offer enough resolution to show secondary peaks.

The fact that the coastdown test peak is shifted left of the rundown test peak may be attributed to poor resolution, or it may be due to a vibration analyzer response time which is too slow to handle the rapid deceleration from 3000 to $2500 \mathrm{rpm}$. 
Attachment 5, page 2 of 2

\section{COASTDOWN vs. RUNDOWN COMPARISON}

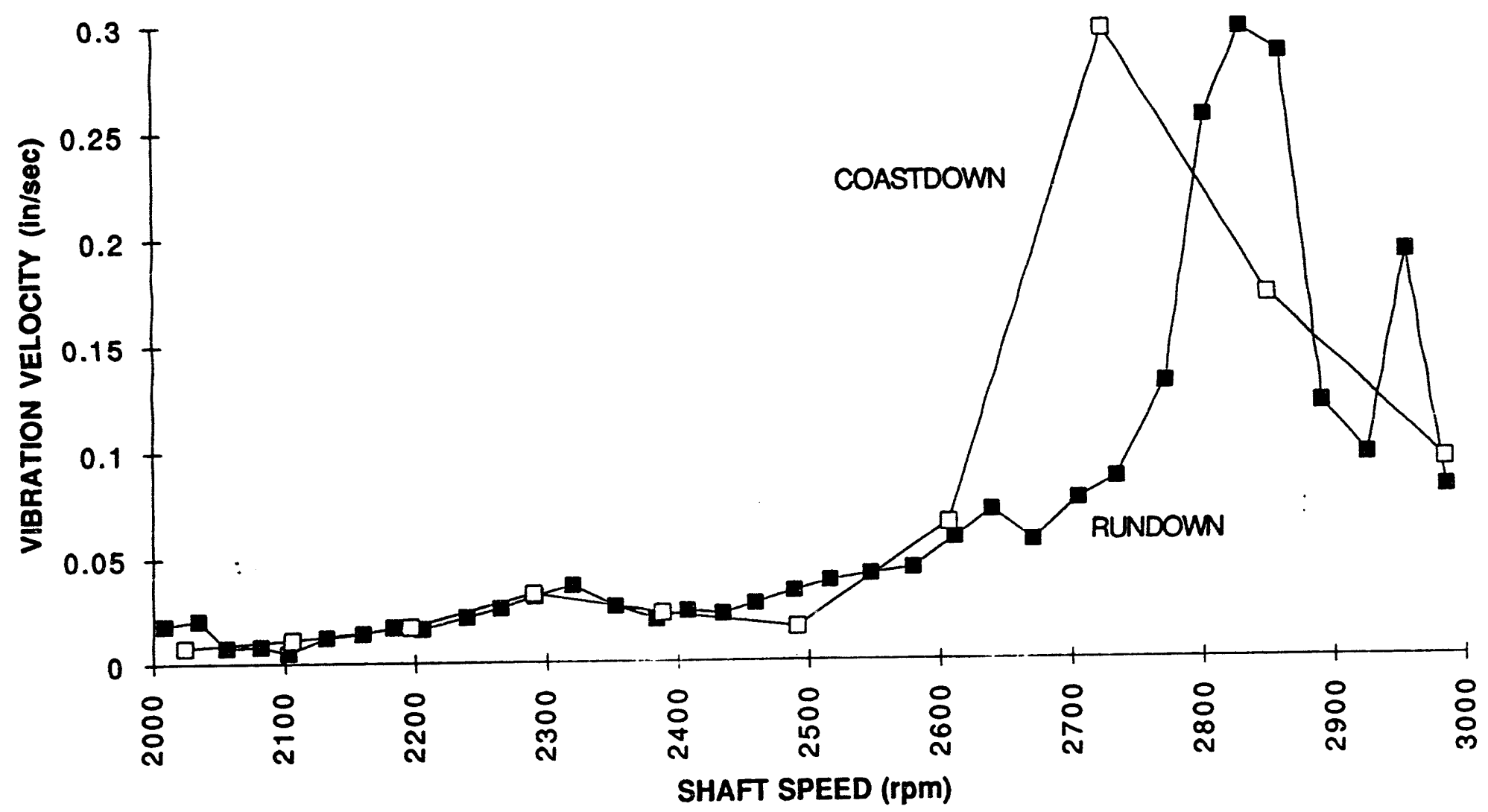




\section{Attachment 6, page 1 of 2}

\section{Summary}

Data from the tests discussed in this report are presented in tabular form on page 2 of this attachment. The effects of variations to the parameters of tank-top loading, operable pump, and tank water level are presented, and it is shown that tank-top loading and operable pump significantly affect vibration, while tank liquid level has a relatively smaller impact. Also, natural frequencies measured on both pumps when both pumps were installed in HPT10 are compared, and it is shown that the natural frequencies are very close. 
Attachment 6, page 2 of 2

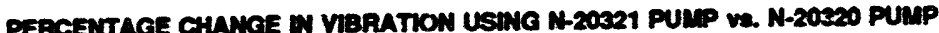

\begin{tabular}{|c|c|c|c|}
\hline & \multicolumn{2}{|c|}{ OVERNLL VERATION } & \multirow[b]{2}{*}{ XCHWCE } \\
\hline & $\mathrm{N}-20320$ & N-20321 & \\
\hline TEST1-TEST3 & 0.22 & 0.05 & $-77 x$ \\
\hline TESTT-TESTB & 0.20 & 0.07 & $-65 x$ \\
\hline TEST2-TEST4 & 0.37 & 0.09 & .786 \\
\hline TEST7-TEST & 0.43 & 0.14 & $-67 x$ \\
\hline & STDD & & $\begin{array}{r}-71 \% \\
6 \%\end{array}$ \\
\hline
\end{tabular}

PEAK VEAATION
\begin{tabular}{|r|r|r|}
\hline N-20320 & N-20321 & XCHANCE \\
\hline 0.53 & 0.16 & $-70 \%$ \\
\hline 0.52 & 0.17 & $-67 \%$ \\
\hline 1.54 & 0.60 & $-61 \%$ \\
\hline 1.77 & 0.55 & $.69 \%$ \\
\hline
\end{tabular}
AVOX CHANCE
STD DEMATION

PEACENTACE CHANCE WI VERATON FOR 2 PUMPS BSTALLED IN HPTIO v. 1 PUMP

\begin{tabular}{|c|c|c|c|}
\hline & \multicolumn{2}{|c|}{ OVEPNUL VERATION } & \multirow[b]{2}{*}{ XCHWG } \\
\hline & 1PUNP & 12PUMPs & \\
\hline TEST1-TEST2 & 0.00 & 0.05 & $-44 x$ \\
\hline TEST3-TESTA & 0.37 & 0.22 & $-41 x$ \\
\hline TESTB-TESTR & 0.14 & 0.07 & $-50 x$ \\
\hline TEST8-TESTP & 0.43 & 0.20 & $.53 \%$ \\
\hline
\end{tabular}

STD DEMATION
PeAK VERation

\begin{tabular}{|l|l|l|l|}
\hline PUNP & 2PUWPS & XCHWKEE \\
\hline
\end{tabular}

\begin{tabular}{|l|l|l|l|}
\hline 0.60 & 0.16 & $.73 x$ \\
\hline
\end{tabular}

\begin{tabular}{l|l|l|}
\hline 1.54 & 0.53 & $-66 \%$ \\
\hline
\end{tabular}

\begin{tabular}{l|l|l|}
0.55 & 0.17 & $-69 x$ \\
\hline 1.77 & 0.52 & $-71 \%$ \\
\hline
\end{tabular}

\begin{tabular}{l|l|l|l|}
\hline 1.77 & 0.52 & $-71 \%$ \\
\hline
\end{tabular}

AVG\% CHANEE STD DEVATION
$-70 \%$

$3 \%$
COMPARLSON OF PFUMAYY MATURAL FREOUENCES WTH TMO PUMPS IUSTALLED W HPTIO

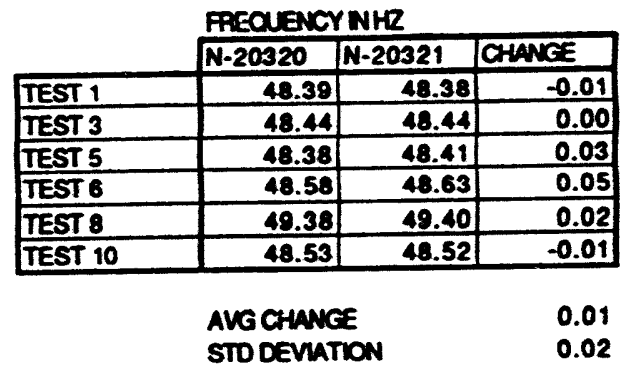

MOTES:

1. Overall vibration is calculatad by aumning the peak vbration values during cosedidown from $3000 \mathrm{rpm}$ to $2000 \mathrm{rpm}$ and dividing by the number of empibe.

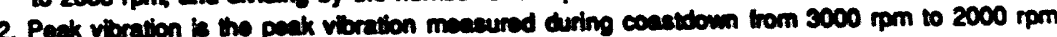

PERCENTACE CHANCE IN VIBRATON FOR TANK LEVEL 85 MCHES W. 65 WCHES

\begin{tabular}{|c|c|c|c|}
\hline & \multicolumn{3}{|c|}{ OVERNLL VBPATION } \\
\hline & 85 MCHES & 65 NCHES & XCHWEE \\
\hline TEST1-TESTE & 0.05 & 0.07 & $40 x$ \\
\hline TEST2 - TESTT & 0.09 & 0.14 & $56 \%$ \\
\hline TEST3-TESTR & 0.22 & 0.20 & $-0 x$ \\
\hline TESTA-TESTP & 0.37 & 0.43 & $16 \%$ \\
\hline
\end{tabular}

PEAKVIBRATION

85NCFES 65 NCFES $\%$ CHANGE

\begin{tabular}{|c|c|c|}
\hline 0.16 & 0.17 & $6 \%$ \\
\hline 0.60 & 0.55 & $-8 \%$ \\
\hline 0.53 & 0.52 & $-2 \%$ \\
\hline 1.54 & 1.77 & $15 \%$ \\
\hline
\end{tabular}

AVG \% CHANGE

$26 \%$

AVG \% CHANCE

STD DEVATION

$3 \%$
$10 \%$ 


\section{Attachment 7, page 1 of 2}

\section{Summary}

The vibration velocity vs. pump speed plot shown on page 2 of this attachment defines the revised acceptance criteria for the NWTF Transfer Pumps. The revision was necessitated by design technical specifications for pump procurement which allowed vibrations higher than the previous acceptance criteria of $0.2 \mathrm{in} / \mathrm{sec}$, which is based on current SRS guidelines. 
Attachment 7, page 2 of 2

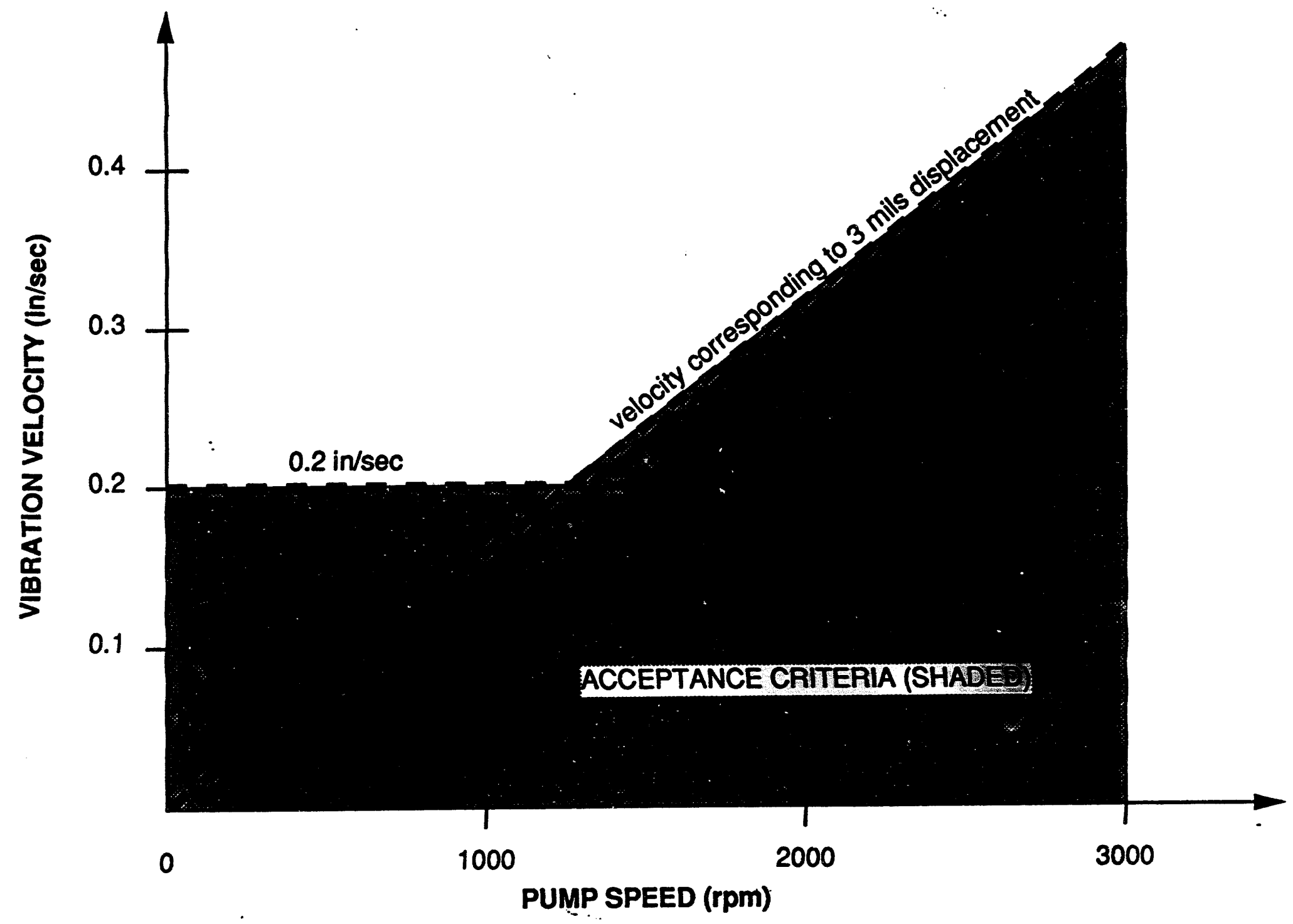



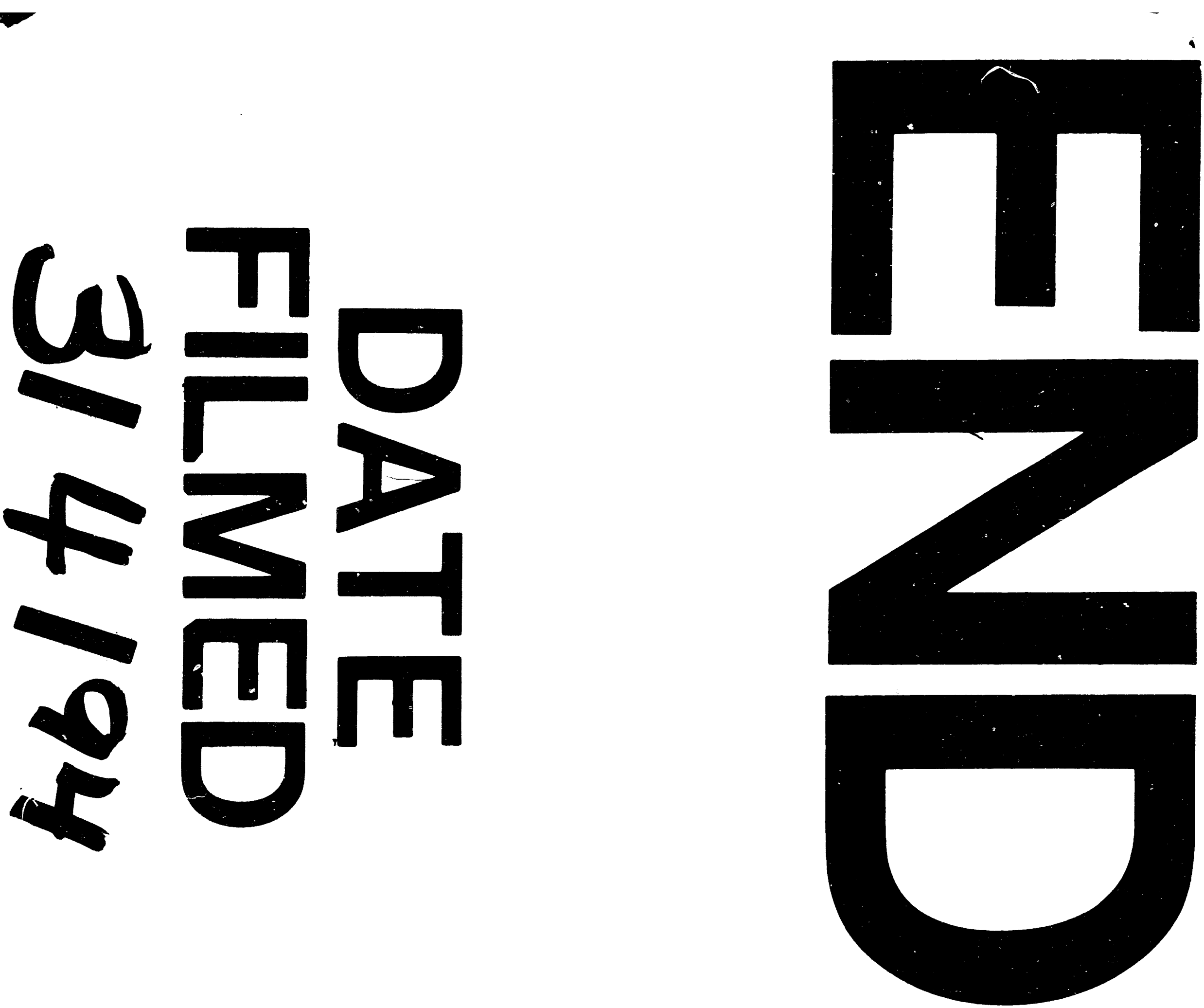


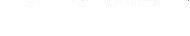

